\title{
Weaving meanings from the deliberative process of collegiate management in nursing ${ }^{1}$
}

\author{
Giovana Dorneles Callegaro Higashi \\ Alacoque Lorenzini Erdmann ${ }^{3}$
}

Objective: to understand the meanings of the collegiate deliberations attributed by its members on an undergraduate nursing course. Method: Grounded Theory, interviews being held with 30 participants, making up 4 sample groups, between January and June 2012, in a public higher education institution. Result: 5 categories emerged, indicating the phenomenon and weaving the paradigmatic model: Understanding the experience of the complex relationships and interactions in the deliberations of collegiate management in nursing: intertwining divergences, convergences, dialogs, collectivities and diversities. This deliberative process presents various meanings involving discussion, and divergent, convergent and complementary positions, through dialog, commitment and negotiation. Conclusion: the deliberations in the collegiate of nursing, intertwining dialogs, collectivities and diversities, mold the complex relational fabrics.

Descriptors: Education, Higher; Organization and Administration; Decision Making; Nursing.

\footnotetext{
${ }^{1}$ Paper extracted from master's thesis "Weaving meanings in collegiate management of an undergraduate degree in nursing from the perspective of complexity", presented to Universidade Federal de Santa Catarina, Florianópolis, SC, Brazil.

${ }^{2}$ Doctoral student, Universidade Federal de Santa Catarina, Florianópolis, SC, Brazil. Scholarship holder from Coordenação de Aperfeiçoamento de Pessoal de Nível Superior (CAPES).

${ }^{3} \mathrm{PhD}$, Full Professor, Universidade Federal de Santa Catarina, Florianópolis, SC, Brazil.
}

Corresponding Author:

Giovana Dorneles Callegaro Higash

Rua João Pio Duarte Silva, 114, Apto. 201, Bloco A

Bairro: Corrego Grande

CEP: 88036-070, Florianópolis, SC, Brasi

E-mail: gio.enfermagem@gmail.com
Copyright $\odot 2014$ Revista Latino-Americana de Enfermagem This is an Open Access article distributed under the terms of the Creative Commons Attribution Non-Commercial License (CC BY-NC).

This license lets others distribute, remix, tweak, and build upon your work non-commercially, and although their new works must also acknowledge you and be non-commercial, they don't have to license their derivative works on the same terms. 


\section{Introduction}

Globalization, technology and information have strongly influenced the human living process, with repercussions in the social, educational, political, economic and cultural spheres, while at the same time promoting new constructions and discussions regarding university management, both in the political sphere and in the academic context ${ }^{(1)}$.

The complexity of contemporaneous society has encouraged the appearance of new processes and models of education, curricula and active methodologies in the process of teaching, learning and managing through new managerial approaches - such as, for example, collegiate management. In this way, breaking with the traditional management of the past - based on control and certainty - and incorporating new models into practice, in a shared and participative perspective, is beneficial for the development of lecturers, students and other persons involved in the organization/ environment. To accompany the advance and new requirements in the training of health professionals, in particular nurses, it is necessary to put into effect changes in the teaching-learning process, adapting the individual to the contemporary context, above all to the complexity and unpredictability which are characteristic of work in health(2).

The university is characterized as a privileged locus which favors the production, appropriation and socialization of knowledge, so as to aggregate, foster, build and encourage the production of science, technology and innovations, with a view to driving individuals' training and qualification. Seen from this angle, the university ${ }^{(3)}$ is part of a civil society able to guarantee liberty, equality, justice and the possibility to live well. In this regard, the university is developed through the intertwining of its relational and functional dynamics; with the formal and administrative structure simply supporting this set(4).

The collegiate management model has stood out among the managerial practices used by higher education institutions (HEI) since the 1970's. Therefore, collegiate management is configured as a "new" management model used in HEI, in its turn understood as a collective, deliberative and autonomous structure which seeks to share decisions for the resolution of problems and demands which emerge in this scenario.

The collegiate represents a new management model whose main characteristics are the decentralization of decision-making, and the bringing-together and plural participation of the actors involved in the context ${ }^{(5)}$. Thus, decision-making becomes part of the routine work of the nursing professional. The participation of the lecturers and students in the collegiate takes on a fundamental importance, as it increases the administrative, pedagogical and deliberative conduct, supported legally by norms and institutional regulations. The decisionmaking process is participative, collective and shared by the representatives of the collegiate, who are immersed in a complex fabric of interactions and associations, of knowledge between the parts and the whole, the whole and the parts, and the parts among each other, with a backdrop of retro-activities and recursivity of actions, relationships and retro-actions ${ }^{(6)}$.

In this scenario, it is considered important to produce new knowledge regarding collegiate management and the deliberative process, so as to strengthen decisionmaking in a shared, democratic and participative way, and above all to lever professional training toward excellence. To this end, the question is made: What are the meanings of the collegiate deliberations, attributed by its members on an undergraduate nursing course? Understanding the meanings of the collegiate deliberations attributed by its members on an undergraduate nursing course was established as an objective.

\section{Methodology}

This is a qualitative study, anchored in the Grounded Theory (GT) of Strauss and Corbin ${ }^{(7)}$. It was undertaken in a public university in the south region of Brazil, in February - June 2012, through intentional selection and individual, semi-structured interview. Study members were: lecturers, students and staff involved directly and indirectly with the collegiate of the nursing course, divided into four sample groups, totalling 30 participants.

The data was collected and analyzed concomitantly. Through the saturation of the first sample group, new hypotheses and questions were constructed, advancing and deepening the content, leading to the next sample group, and so on, successively to the other groups. Based on the character of the training of the sample groups, the phenomenon (central category) and respective paradigmatic model emerged.

The first sample group was made up of six lecturers who were part of the collegiate of the undergraduate nursing course. To be part of this, it was necessary for the lecturer to have experienced functioning in the collegiate of the undergraduate nursing course. The 
research began based on the following initial question: Tell me about the meaning of the collegiate deliberations on the undergraduate nursing course. The elaboration of the subsequent questions was directed based on the interviewees' responses.

The second sample group was achieved with 11 participants. The inclusion criteria were to hold management/coordination positions and to have experiences with a deliberative scope. Hypotheses emerged indicating that the collegiate is a scenario ruled by norms, regulations and laws, which allow the construction of relationships and interactions between peers with an interface between lecturers from other departments who lack experience in the collegiate. The guiding question was: what is the meaning of the deliberations and of the collegiate experience on the nursing course?

The third sample group was made up of eight participants, with the inclusion criteria for this group being: to be a lecturer on the nursing course, but to be a member of another department. The hypothesis was that relationships and interactions are constructed between the collegiate's lecturer and student representatives. Thus, a fourth sample group was made up, with five student participants, divided among those with and without experience in the collegiate.

The interviews, as they were held and transcribed, were inserted into the NVIVO ${ }^{\circledR}$ software(8), allowing the organization and classification of the information collected. The collection and analysis of the data occurred simultaneously, following the stages proposed by GT: open, axial and selective codification. In this way, the codes were being regrouped, giving rise to the categories and subcategories(7).

The codification and analysis of the data led to the identification of five components (context, cause, intervening condition, strategies and consequences), in accordance with the paradigmatic perspective of Grounded Theory, supporting the phenomenon and weaving the paradigmatic model: Understanding the experience of the complex relationships and interactions in the deliberations in collegiate management of nursing: intertwining divergences, convergences, dialogs, collectivities and diversities.

The first category Constructing the web of meanings and interfaces of the collegiate experience characterized the phenomenon's context, with four subcategories. The second category Investigating the diversity which permeates the collegiate management and the training process in the nursing course represented the phenomenon's causal condition, with one subcategory. The category Detecting the collegiate deliberations in a plural and singular perspective was the strategy, with five subcategories. The category Communication and conflict management in the process of deliberations collegiate sphere was the intervening condition, constituted by two subcategories. The category Emphasizing the collegiate's importance for strengthening professional training guides towards the consequence of the phenomenon, with three subcategories.

The study was approved by the Ethics Committee for Research Involving Human Beings, under decision n. 2285/11. The ethical aspects were respected at all stages of the research, as required by Resolution 196/96 of the National Health Council. The participants' accounts were identified with the letters "GA, GB, GC" followed by an ordinal number (e.g: GA.1; GA.2; GB. 3; GB.4...).

\section{Results}

The codification process and the constant comparison of the data, added to the theoretical sensitivity, made it possible to identify the study phenomenon. The categories and their respective subcategories are presented below, immersed in the plurality and singularity of the relationships, interactions which permeate the university management process.

\section{Constructing the web of meanings and interfaces of the collegiate experience}

The category was made up of three subcategories. The first subcategory was identified Signifying the experiences in the collegiate of the nursing course. The accounts reveal the meanings attributed to the collegiate experience, such as evaluation, organization and resolutive capability:

The meaning of the collegiate is to evaluate the course so as to know its strengths and weaknesses (GA02).

It means organization, the ability to resolve problems, it is an interlocution between different opinions (GA06).

The collegiate has the meaning of commitment, it seeks to develop the best among the colleagues, with the colleagues, for the colleagues, principally for the students (GC13).

In contrast, in the second subcategory Perceiving the collegiate management as a shared and participative space, the participants reveal contradictory statements in relation to shared management in the collegiate.

You share the decisions, tasks, elements of the professional's formative process (GD20) 
The collegiate, I see it as going there and voting, deciding $A$ or $B$, always two paths, there's no shared management (GA05).

I see it as a time for voting, not as shared management (GB12).

The third subcategory is titled Characterizing the collegiate as a space of representativity. In this subcategory, the participants reported that the collegiate makes it possible for the lecturers and students to become closer:

It's important to bring the students to the meeting more, for greater closeness among the students to bring them to the decision spaces (GE22).

\section{Investigating the diversity which permeates the collegiate management and the training process.}

This category presents the subcategory: Co-existing with the diversity which intertwines the collegiate management and the professional training. For the participants, working with diversity is co-existing with plurality, flexibility and ambiguity:

Dealing with diversity is: one wants to go north, the other wants to go south, one thinks something is yellow, the other that it is red, one rigorously defends principles, and the other their flexibilization. How should one deal with this? It's difficult, there's no magic formula or recipe (GC15).

We have a variety of people with different origins, but with a common object (GD17).

It is in the pluralities of the experiences that one builds the best possibilities for the training (GC13).

\section{Detecting the collegiate deliberations in a plural and singular perspective}

This category is divided into five subcategories. The first subcategory, "Giving meaning to the deliberations in the organizational context of the collegiate" shows the meanings reported by the study participants, which emerge from their experiences in the collegiate which support the professional practice, as shown in the accounts below:

The meaning of being a practical, concrete and nonbureaucratic commitment to formal decision-making (GB7).

It means a process of discussion and decision-making by a group which is responsible for implementing those ideas, the model, the structure which was agreed, a deliberation always goes through definitions and choices (GA3).

I think it means resolving, the issue is resolutive capacity, it is finding the path and the exit (GA6).

The second subcategory is termed "Explaining the deliberative process and the consensus in the collegiate". The participants indicated that the deliberative process requires knowledge and understanding of the reasons for which one is deliberating, as there are no single choices, as may be observed in the statement below:

If I have a question to be considered, I have to understand the question, make a context of the question, one needs to think about the possible alternatives, I don't think there is just one path, there are multiple choices and one will always be correct, looking on one side, another may be more correct, looking on the other side, you have to think about the impact for the course and the collective (GC14).

The participants emphasized that it is difficult to work with the consensus, which is coupled with the diversity and is constructed in the plurality, as shown in the accounts below:

There can only be consensus if there is diversity. Where there's no diversity, what sort of consensus is that? (GE22).

It's difficult to work with the consensus, because in order to negotiate, you need to yield, and this isn't always accepted in our culture, we are dealing with values, and values have to do with subjectivity (GC13).

The third category is "Being familiar with, and complying with, the legislation in the collegiate sphere of the nursing course". The accounts evidenced the importance of having information and knowledge on normative laws and regulations:

There are people who are well-informed about the new legislation, the university, the nurse (GB12).

As a process of debate is important, and people are grounded in the norms, in the laws, in their knowledge, in their experience, this all helps in relation to the training, in the understanding of what a teaching-learning process is, at the end of the day, this set of ideas forms a deliberation (GC15).

The fourth subcategory was identified as "Deliberating collectively in the nursing collegiate." The participants revealed that the collective, articulated and participative work boosts new relationships and interactions:

I have no doubts that doing things collectively, articulated and participatively affords new possibilities for relationships between the actors involved in the process, improving the dialog and the co-existence in the university (GA02).

When you make a decision listening, discussing, making it together with the people involved, it is more solid, it's better grounded, it gives security and support (GB10).

In the fifth subcategory, "Indicating strategies for deliberating in the collegiate", the participants reported informed deliberation and planning in a perspective of continuous flow as strategies: 
The strategy is planning which comes from continuous flow, so as to see the people's interlocution (GA03).

I believe in informed deliberation, you can only judge or give opinions on what you know (GE21).

\section{Communication and conflict management in the process of deliberation in the collegiate sphere.}

In the first subcategory, "Living with the conflict/ divergences/convergences in the collegiate professional relationships", the participants indicated the need to understand the conflict as a "device for transformations", that is, as a possibility for renewal and changes in the organizational dynamicity.

The first question of the conflict is to confront and understand it as a device, a trigger for the transformation. This is the richness of the different possibilities for resolving a conflict (GE22).

Furthermore, the conflict is constructed in the interpersonal relationships established in the complex organizational spaces, as the accounts below illustrate:

Conflict is part of relationships and it's not always easy to understand this when you are in one, because when you are in a conflict the emotions are disturbed. Its origin almost always seems to be in divergence (GB13).

In the second subcategory, "Detecting the dialogic perspective and communication in the intertwining of the/in the professional relationships of the collegiate organization", the participants expressed that in the collegiate, the dialog, the interlocution and the exchanging of information present weakness, principally among the students:

The interlocution with the community of students and professors is very weak, because there is a lower number of representatives (GB09).

I emphasize and reiterate that sometimes there is little dialog in the collegiate (GE23).

I see that within the collegiate, the communication is little effective (GB12).

\section{Emphasizing the collegiate's importance for strengthening professional training}

In the first subcategory, "Having professional work in defense of nursing", the statements express the concern of the collegiate's representatives with training professionals with knowledge, technical and cognitive aptitudes, and skill:

We work so that, at the end of the day, one obtains a professional who is as well trained as possible (GA02).

We are training people with technical, political and philosophical competences and skills (GA06).
I am concerned about the nurse's professional training, the nurse has to know biology, pathologies, anatomy, even if he isn't going to work in hospitals (GA04).

The second subcategory "Experiencing the transition of the students' profile and their participation in the collegiate of the nursing course", the statements indicate changes in the social scenario which are reflected in the professional practice and entail new relationships and perspectives in the world of work in an emerging context:

The participation is important, you can't think about training without thinking about the student (GB07).

My students have been different for 35 years, new values have been engendered, and new perspectives on life, there are new technologies which allow new relationships, and at the moment, other things are being developed (GC13).

The third subcategory is "Revealing the actions deliberated in the collegiate and the training process on the nursing course." The participants revealed that the actions and the deliberations of the collegiate cover technical, administrative, didactic and pedagogical aspects which aim to meet the curricular dynamics and the needs of the lecturers, the students and the institution.

If an issue is put in debate, to be deliberated, it was created as a need of the students, the professors and the institution (GB10).

The student/professor relationship, changing course, the arrival of new students, the welcoming of new students, graduation, changing from one university to another (GE25).

The fourth subcategory was "The undertaking of pedagogical training in the collegiate sphere being necessary". The participants emphasized the need for pedagogical training and technical instrumentalization so as to improve their pedagogical actions.

The professor's work is bureaucratic, it falls to the collegiate to do the professor's pedagogical training (GE23).

Proposing workshops, discussing the evaluation instrument pedagogically, pedagogical strategies, the way to construct the nursing (GC18).

A technical instrumentalization of how occurs, from the theoretical point of view, for knowledge on the management process, on how to manage conflicts, on how to work with shared decisions (GB09).

The relationships and the integrations between the categories and subcategories resulted in the phenomenon and paradigmatic model represented in the figure below. 




Source: HIGASHI, 2012

Figure 1 - Representation of the phenomenon and paradigmatic model: Understanding the experience of the complex relationships and interactions in the deliberations in collegiate management in nursing: intertwining divergences, convergences, dialogs, collectivities and diversities

\section{Discussion}

Each participant was singular and plural in giving his or her perceptions, understandings and meanings regarding the collegiate and deliberative experience, such that the inference is possible that the collegiate management is immersed in a web of multiple, distinct and complex meanings. Based on the participants' experiences, meanings were issued regarding the deliberations in nursing, anchored in objectivity and subjectivity, which permeate relationships, interactions and associations of a dynamic, fast-moving and complex scenario( ${ }^{(8)}$.

In this regard, one study revealed meanings on the work for lecturer-managers, such as, for example, that the same made possible the construction of life projects and helped to maintain their individuality. On the other hand, it could create personal dissatisfaction in such a way as to reflect on the individual's process of living(3). The work activities must impact positively on the individual's life, as this increases the personal satisfaction and professional success.
The collegiate, for the study participants, is a deliberative space based on commitment and responsibility for personal, academic, professional and institutional development. Thus, how each individual defends and declares his or her interests places them sometimes in opposing positions, and sometimes as partners. One study indicates that communication and dialog between the different sectors and segments of society are necessary, as they bring the different contexts closer and viabilize more concrete, appropriate and viable solutions in the individual and collective ambit $^{(9)}$.

For the study's participants, communication and dialog must occur effectively and globally. Furthermore, the information must not be limited or fragmented, as it can obscure and limit the possibility of discerning what is real. This result corroborates a study which also described difficulties in the communication process impacting negatively on the organization's personal and work relationships ${ }^{(3)}$.

The participants revealed contradictory understandings regarding shared decision-making. In this perspective, the sharing of actions, referrals, 
activities and decisions for collegiate deliberations and professional training is viabilized. In contrast, it can create exclusion and isolation, fragmenting the relationships and decision-making power to the detriment of some individuals. The challenge is to strengthen the participation of a heterogeneous collective, as diversity is necessary to support deliberative processes.

As its backdrop, the decision-making process has complexity, with diversity, divergences, convergences, contrasts and complementarities. In this perspective, one study emphasizes that the deliberation reflects the complexity, as it covers the uncertainty, the subjectivity and the plurality of the relationships and human and work interactions immersed in the organizational environment ${ }^{(10)}$. Deliberating entails strategies, dialog, sensitivity, creativity and understanding of the social, economic and political reality, based on laws and rules of the university management.

Although consensus was constantly addressed by the study participants as being something important, in some situations voting is necessary in the collegiate. The collegiate actions aim to meet the needs of the students, lecturers, staff and institution, with their unique characteristics and those they have in common. At the end of the day, based on the building of deliberative processes based on the consensus, one can minimize the appearance of conflicts.

In the statements, some strategies for the deliberative process were indicated, such as planning; however, they confirmed the need for strengthening and consolidation of the planning in a more incisive way. One study emphasized the need to implement strategic planning in the university ambit, university planning entails predicting and meeting human, economic (financial) and material needs, in relation to the academic spheres and the administrative bodies ${ }^{(11)}$.

For the participants, conflict is a "trigger for change" which is built in the weaving of relationships and interactions. A similar result may be detected in another study which revealed that, very often, conflict is frequent in the exercising of management, it being necessary to observe and administrate the situations which can hinder or affect the performance of the management, with a view to encouraging the collective growth and development ${ }^{(12)}$.

In this regard, one study indicates other conflicts experienced by university managers, such as, for example, in the management of people, administration of the dissatisfaction of, and conflicts between, staff, in bringing together the lecturers, among others.
Furthermore, the university managers dedicate a large part of their time to resolving problems, from the academic-administrative context, through to the dimension of personnel, lecturers, students and staff(13). It is necessary to recognize the situation of conflict and proactively to seek to listen, evaluate, reflect and act appropriately so as to resolve it.

Conflict can emerge in any organization, appearing among the relationships, the interactions in the coexistence between the individuals, whether in the work, family or social environment. In this regard, conflict must not be considered only in the democratic theories, but as a constitutive and constructive element of the public debate ${ }^{(14)}$. After conflict, it is necessary for there to be reorganization, planning and new work actions, so as to strengthen the relationships and interactions between the professionals.

The representation viabilizes the individual's participation in the decision-making process in the organizations. When a group is representatively fragmented, it may meet difficulties and become fragile, in relation to collective debate and discussion. The broadening of the link and of the commitment legitimates the representation, and consequently strengthens the organizational dynamicity ${ }^{(9)}$.

In the collegiate, the democratic participation is beneficial for an education based in the diversity and plurality of its representatives. The collegiate can increase the broadening of the knowledge and the information through new relationships and interactions based on the multiple dimensions of being, knowing and co-existing in a global and complex perspective. In this way, the lecturer can also contribute to the construction and training of a professional directed towards excellence in university management and, in a general way, in the exercising of nursing, endowed with knowledge, ethics, qualified, reflexive criticism, with technical skills and scientific knowledge, as well as being a being who values complex aspects immersed in the human subjectivity.

\section{Conclusion}

The categories found in the study were: Constructing the web of meanings and interfaces of the collegiate experience (context); Investigating the diversity which permeates the collegiate management and the training process (causal condition); Detecting the collegiate deliberations in a plural and singular perspective (strategy); Communication and conflict management in the process of deliberations collegiate 
sphere (intervening condition); and Emphasizing the collegiate's importance for strengthening professional training (consequence).

In summary, the categories found indicate that the collegiate is a deliberative space which needs the collective and shared participation of its representatives, in which conflict and dialog weave a complex web of meetings and discrepancies, of pluralities and singularities. The phenomenon found, and the paradigmatic model, is titled: "Understanding the experience of the complex relationships and interactions in the deliberations in nursing collegiate management: intertwining divergences, convergences, dialogs, collectivities and diversities".

The deliberative process presents various meanings, which involve discussion, divergent, convergent and complementary positions, commitment and negotiation. The collegiate is a space directed at the administrative, pedagogical and deliberative dimensions, for personal and professional training. It is concerned with contributing effectively to the cognitive, political, cultural, social, technical and scientific training, so that this professional may be an agent who produces, constructs, and transforms her social reality and practice.

In the collegiate, the student and lecturer participation, among others, permits disruptions and oppositions, with conflict situations possibly emerging, which were seen as ingredients and beneficial for the development of the collective. The deliberative processes go through fluctuations, reversals and advances, which require participation and commitment in the collective activities and actions for the development of the collegiate and professional training. This points to the importance of establishing decentralized, consensual, democratic deliberative processes based in participation and diversity.

Emphasis is placed on the poor participation of the representatives in the collegiate, and on the shortage of communication and of planning strategies in the university management. In this way, it is important to drive forward the process of training the nurse through knowledge and aptitudes for working with the collective, in conflict, in diversity, among divergences; to drive forward the training of skills for deliberating in a shared way based on plural participation between/ with the actors involved in this context, strengthening the construction of new methodologies, strategies and knowledge for quality in the training and in the exercising of the profession.

\section{References}

1. Calderon AI, Pedro RF, Vargas MC. Responsabilidade social da educação superior: a metamorfose do discurso da UNESCO em foco. Interface. 2011;15(39):1185-98.

2. Silva KL, Sena RR. Ensino de enfermagem: buscando a formação crítico-reflexiva e as competências profissionais. Rev. Latino-Am. Enfermagem. 2006;14(5):755-61.

3. Sampaio RM, Laniado RN. Uma experiência de mudança da gestão universitária: o percurso ambivalente entre proposições e realizações. Rev Adm Pública. 2009;4(1):151-74.

4. Kanan LA, Zanelli, JC. Envolvimento de docentesgestores com o trabalho no contexto universitário. Psicol Soc. $2011 ; 23(1): 56-65$.

5. Bernardes A, Cecilio LC de O, Évora YDM, Gabriel CS, Carvalho MB Modelo de gestão colegiada e descentralizada em hospital público: a ótica da equipe de enfermagem. Rev. Latino-Am. Enfermagem. 2008;19(4):1003-10.

6. Morin E. A cabeça bem-feita: repensar a reforma, reformar o pensamento. $15^{\mathrm{a}}$ ed. Rio de Janeiro: Bertrand Brasil; 2008.

7. Strauss A, Corbin J. Pesquisa qualitativa: técnicas e procedimentos para o desenvolvimento de teoria fundamentada. 2. ed. Porto Alegre: Artmed; 2008.

8. Morin E. Os sete saberes necessários à educação do futuro. 11 ed. São Paulo: Cortez; Brasília: UNESCO; 2006.

9. Coelho JS. Construindo a participação social no SUS: um constante repensar em busca de equidade e transformação. Saúde Soc. 2012, 21(1):138-51.

10. Shimizu T. Decisão nas organizações. 2 ed. São Paulo: Atlas; 2006.

11. Moritz M, Moritz GO, Melo MB, Silva FM. A implantação do planejamento estratégico em organizações complexas: o caso da Universidade do Estado de Santa Catarina. Rev Gual. (Florianópolis);5(1):228-49.

12. Guerra ST, Santos JLG, Prochnow AG, Silva DC, Silva RM, Leite $\mathrm{JL}$, et al. O conflito no exercício gerencial do enfermeiro no âmbito hospitalar. Rev. Latino-Am. Enfermagem. 2011;19(2):362-9.

13. Marra AV, Melo MCOL. A prática social de gerentes universitários em uma instituição pública. Rev Adm Contemp. 2005;9(3):9-31.

14. Pereira MA. Movimentos sociais e democracia: a tensão necessária. Opin Pública. 2012;18 (1):68-87. 